\title{
Instructor-Librarian Cooperation in the Social Sciences
}

Some teaching possibilities for college libraries as seen by an instructor at Whittier College.

$\mathrm{T}$

HE COLLEge TEACHER in the social sciences who desires to facilitate the learning process in the student rather than to indoctrinate him by the lecture method quickly finds himself faced with the problem: How can the best use be made of library personnel and materials?

We are developing a technique at Whittier College which almost eliminates lecturing and enables the student to arrive at opinions based on his own reading and thinking. Extensive use is made of the library, and it is this phase of the experiment I propose to discuss.

Our program is based on the belief that history teaching is the proper handling of "content." Two principles have guided us in evolving a method: ( $\mathrm{I}$ ) the student should read carefully as much material as possible in the time which is available; (2) formal classroom lectures should be abandoned in favor of "directed reading." Translating these principles into action has resulted in the transfer of the student from the classroom to the library.

The plan for the course which deals with Europe during and between two wars, 1914-4-, will serve as an illustrative example. The usual semester of seventeen weeks (not counting examination week) is divided into five units, with one week for introduction and one for review. During the first week the mechanics of the course are explained and a general survey of the period is presented. Each student takes an intensive examination, the results of which serve the teacher in future counseling.

The class never meets in a "classroom." The librarian ${ }^{1}$ has made available a small office for personal counseling and a seminar room for weekly meetings. After the introductory period for each unit every student receives a question list designed to fill in the gaps in his knowledge of the unit (as indicated by the preliminary examination). Since the course is for three credits, at least five hours a week are spent reading in addition to a one-hour seminar. Experience has shown that the average student must read seven hours to complete the questions adequately. There is no textbook since it is the purpose of the seminar on the first day of the week to bring out the continuity of the material as well as to emphasize the salient points.

Arriving in the library the student finds a special shelf of materials dealing with that week's assignment. The teacher, now a "guide," has gathered together in one place most of the books on the subject and has compiled, with the assistance of the librarian, a comprehensive list of magazine articles and pamphlets. This bibliography is not a "controlled" list; it is a guide. The difference between "control" and "guidance" may be likened to the driver of the herd as opposed to the shepherd of the

${ }^{1}$ Wilma Bennett, acting librarian. 
sheep. The purpose of guidance is to make representative materials available, not to neglect some and to exploit others.

\section{Student's Introduction}

Meeting the materials for the first time the student is encouraged to examine each book and judge its general worth as well as its pertinency to his list of questions. It is suggested that he note certain information about the book, such as its title, author, purpose (as indicated in the preface), and date (significance in relation to time written). The instructor-librarian (this term is used to indicate the cooperative action of the instructor and librarian in assisting the student), having read the books or critical reviews on them, is present to offer additional help in determining the relation of the book to the information sought. The teacher is also present to assist in clearing up confusion aroused by contradictory statements or to indicate other sources in addition to those collected by the instructorlibrarian. The teacher has regular hours in his library office, and students are encouraged to drop in and discuss their work.

Thus, during a unit each member of the class spends at least fifteen hours in library reading and three hours in seminar, in addition to the time spent in consultation. At the end of the unit he makes an evaluation of the work he has done. To do this he writes a short summary of the historical period studied and indicates his impressions. This paper is not prepared in formal examination style but after personal counseling with the teacher. As each unit is completed it is related to all the previous periods, so that by the end of the semester the student is ready for an intensive review and over-all evaluation.

Certain library situations arising out of this change in procedure may now be examined. The most obvious result is the new relationship which now exists between library and teacher. In a sense, teacher and class are the guests of the library, or should look upon themselves as such. Rapid adjustment to the rules and regulations already existing, and the creation of new ones, are necessary. On the teacher's part an obligation to counsel his students in the observance of book care, withdrawal, and return must be recognized. The student should learn to respect the efforts of the librarian and staff and impress upon himself the value of the materials he is handling.

This kind of teaching leadership is bound to fail unless the librarian understands what the teacher is trying to do and lends assistance at every point. The teacher owes it to librarian and staff to acquaint them with full details of the course, either by syllabus or weekly discussion.

One feature of this technique is bound to frighten away some teachers. It is the necessity of knowing what materials are available in the library and what can be secured. The instructor-librarian must know everything or else have a suggestion as to how it can be known. The instructorlibrarian should make an exhaustive study of the library, and bibliographies should be prepared. Student awareness of the sources cannot come about unless the teacher has a thorough understanding of the library. Books, newspapers, periodicals, films, learned journals, pamphlets-all these must be studied for their value to the course. It must not be the aim of the teacher to overwhelm the student with a mass of sources, for nothing arouses fear and confusion in the average student more quickly than the sight of an impossible amount of work, supposedly to be done. Rather the instructor-librarian must exercise judgment and guidance in the sense we have already indicated. 
The instructor-librarian must learn to select "representative" materials. All sides of any question should be presented and, by counseling, the student can be trained to look for the signs which point to the attitude most useful for his purpose. A Great Teacher once said that a tree is known by its fruits. In the examination of materials dealing with a political system, for instance, this rule can be applied. It seems obvious that any political organization which prohibits sane vocal, physical, or mental expression is far from democratic. The student who is encouraged to be critical in his reading will not be too gullible.

Finally, the librarian should stand ready to assist the teacher in providing the physical setting necessary. In addition to shelf space for books, the teacher must have a seminar room and an office for consultation. Both of these rooms should be in or adjacent to the library. The physical needs of rooms and equipment are an important consideration, for we have found that enthusiasm in student and teacher varies according to the availability of the materials and the ease with which they are used.

To some observers the plan outlined above may seem to be nothing more than the regular seminar method. It is an adaptation, but its peculiar feature is the immediate guidance by the teacher. Assuming that most undergraduates are not qualified to do completely independent research, this procedure nevertheless lifts teacher and student above the level of the "dishing-out, lapping-up" process so common today.

It is a happy medium designed so that the teacher may have time to encourage the more serious student while preparing him to do graduate research. On the other hand, the student who is taking the course for general culture may read as much as he desires, while the "grade and credits" student may pursue his inclinations without inconveniencing the others.

In the last analysis, such a plan seems desirable because it brings together the two most important elements in the study of the social sciences-the library and the student.

\section{University Reference Work After the War}

\section{(Continued from page 107)}

be their own detectives and to use the various reference books with freedom of action and with skill. Some departments work a little bibliographical instruction into their courses. Well and good, but what about a general course that will teach the use of the card catalog and the periodical indexes, union catalogs, etc., graded according to the background and training of the student, perhaps covering simple tools the first year, the more advanced ones in the third year, and the specialized ones for the graduate student in a special field in the fourth year?

The already overbusy reference librarian is going to ask, "How can all this be done when we are already overcrowded with work?" Perhaps we need a little examination of our own activities. Are we doing tasks that some other department should be doing? Are we doing bibliographical work already covered by some printed bibliographical service for which we should be subscribing? What can we possibly leave out of our daily schedule that will enable us to have a few more minutes for reading book-reviewing periodicals and other bibliographical publications? With all our desire to push a little harder to make ourselves more efficient, however, we should never forget that our own friendly yet helpful manner is the important factor in working with faculty and students at this critical time in the readjustment of the lives of many young men and women. 